\title{
Catherine Botterel-Michel, L'écrivain ou le singe fin de siècle, «Travaux de littérature» $\mathrm{XX}$
}

Ida Merello

\section{(2) OpenEdition}

\section{Journals}

\section{Edizione digitale}

URL: http://journals.openedition.org/studifrancesi/8037

DOI: $10.4000 /$ studifrancesi.8037

ISSN: 2421-5856

\section{Editore}

Rosenberg \& Sellier

\section{Edizione cartacea}

Data di pubblicazione: 1 juillet 2009

Paginazione: 431

ISSN: 0039-2944

\section{Notizia bibliografica digitale}

Ida Merello, «Catherine Botterel-Michel, L'écrivain ou le singe fin de siècle, «Travaux de littérature» XX», Studi Francesi [Online], 158 (LIII | II) | 2009, online dal 30 novembre 2015, consultato il 11 janvier 2021. URL: http://journals.openedition.org/studifrancesi/8037 ; DOI: https://doi.org/10.4000/studifrancesi. 8037

Questo documento è stato generato automaticamente il 11 janvier 2021.

\section{(c) (i) $\odot$}

Studi Francesi è distribuita con Licenza Creative Commons Attribuzione - Non commerciale - Non opere derivate 4.0 Internazionale. 


\title{
Catherine Botterel-Michel, L'écrivain ou le singe fin de siècle, "Travaux de littérature» XX
}

\author{
Ida Merello
}

\section{NOTIZIA}

CATHERINE BOTTEREL-MICHEL, L'écrivain ou le singe fin de siècle, «Travaux de littérature» XX, 2007, pp. 158-168.

1 L'A. nota come nei personaggi secondari di Maupassant sia frequente la presenza dello scrittore, sempre uomo, basso, ventruto e facilmente calvo, spesso padrone di una scimmia, quasi a rappresentare il proprio alter ego degenerato; un'altra forma di degradazione dello scrittore è rappresentata dallo scriba, altro personaggio ricorrente. Il motivo fondamentale legato allo scrittore è l'impotenza creativa, che nasce da una maggiore consapevolezza esistenziale, tale da portarlo all'ossessione della pagina bianca. La frequentazione dei circoli mondani non è positiva; mentre Maupassant auspica per lo scrittore la solitudine e l'esilio dal mondo. L'A. individua lo scrittore ideale nel diarista di Un cas de divorce, che presuppone una nuova estetica, modellata sull'incompiutezza e la discontinuità del reale. 